\title{
Numerical Study on the Effects of using Nanofluids in Pulsating Heat Pipe
}

\author{
M. Zufar ${ }^{1 *}$, P. Gunnasegaran ${ }^{2}$, Ng K. Ching ${ }^{3}$ \\ ${ }^{12}$ Institute of power Engineering, Universiti Tenaga Nasional, Putrajaya Campus, Jalan IKRAM-UNITEN, 43000, Kajang Malaysia \\ ${ }^{3}$ School of Engineering, Taylor's University, Lakeside Campus, No. 1 Jalan Taylors, Subang Jaya, Selangor, Malaysia \\ *Corresponding author E-mail: zufarm@ymail.com
}

\begin{abstract}
Pulsating Heat Pipe (PHP) is the next generation heat pipe that has a prospect in improving the heat transfer performance. The type of working fluid use in the PHP has a direct influence on the thermal performance. Incorporating nanofluid in PHP may greatly increase its thermal performance as compared to using base fluid (water). The current work focuses on the simulations of 2-dimensional flows in PHP using working fluids such as diamond, silver $(\mathrm{Ag})$, silica oxide $\left(\mathrm{SiO}_{2}\right)$ nanofluids and water. Constant heat flux and filling ratio of $50 \%$ were used throughout the study. From the results, it was found out that diamond nanofluid has the lowest thermal resistance value as compared to other working fluids. The effect of the number of PHP turns was studied and it was discovered that higher number of turns would produce lower thermal resistance value.
\end{abstract}

Keywords: Computational fluid dynamics; Nanofluid; Pulsating heat pipe; Thermal resistance; Volume of fluid

\section{Introduction}

The current development of miniaturized microprocessors has led to excessive heat flux produced from the electronic devices. Heat accumulation in the electronic devices may deteriorate the performance and potentially damage the important internal components [1]. This has motivated researchers and technology leaders to find an effective cooling solution to dissipate the heat dissipated from these devices efficiently. A next generation heat transfer device such as Pulsating Heat Pipe (PHP) is a possible cooling solution for electronic problems. PHP is a two-phase passive heat transfer device which incorporates a working fluid to absorb heat from the evaporator section and dissipate heat at the condenser section. Pulsating flow exists in PHP whereby the working fluid moves throughout the heat pipe without using any external mechanical power. It consists of three sections: cooling section (condenser), heating section (evaporator) and adiabatic section. Movement of working fluid inside PHP is mainly due to the temperature and pressure differences between the evaporator and condenser sections. The fluid relies on its gravity as well to return to the evaporator section [2].

In PHP, a liquid-plug vapor-bubble system is formed. It involves complex heat and mass transfer processes which require very involved and comprehensive analyses. Previous studies had summarized a few important findings. The microcapillary dimensions of PHP would lead to the formation of liquid plugs that have menisci on the plug edges due to surface tension force [3]. Moreover, liquid plug and vapor bubbles could receive heat, reject heat or travel adiabatically in the evaporator, condenser, and adiabatic sections respectively. Lastly, the transportations of liquid plug and vapor bubble in the PHP channel are due to internal pressure pulsations of PHP. Among the factors and parameters that affect the thermal performance of PHP are diameter of PHP channel, number of turns, dimensions, heat input, filling ratio, orientation, and working fluid. Hence, this paper focuses on using different working fluids and number of turns on the 2D PHP model with constant heat flux. By incorporating nanofluid inside PHP, the associated heat transfer rate should be higher as compared to those of the conventional working fluids such as DI water, ethylene glycol and other coolants used in the industry.

Nanofluid is a fluid that contains particles of diameter less than $100 \mathrm{~nm}$ dispersed within a base fluid which is typically water [4]. Nanofluid particles have greater surface area for heat transfer as compared to the conventional working fluids; hence, nanofluid offers better prospect of improving the heat transfer performance. Metals, oxide, carbon nanotube and carbide are nanoparticles that are typically used. Meanwhile, ethylene glycol, water, and oil could be used as the base fluid [5].

$\mathrm{Al}_{2} \mathrm{O}_{3}-\mathrm{H}_{2} \mathrm{O}$ nanofluid has been incorporated in the numerical LHP model by P. Gunnasegaran et al. at various heat inputs and nanoparticle mass concentrations [6]. The result showed that the pressure drop increased with respect to the nanoparticle mass concentration. E. J. Johnson et al. performed the numerical analysis in the 16-turns PHP using water as the working fluid [7]. The result showed the lowest thermal resistance was $2 \mathrm{~K} / \mathrm{W}$ for $50 \%$ filling ratio at a heat input of $50 \mathrm{~W}$. On the other hand, Rudresha et al. conducted numerical and experimental analyses using $\mathrm{SiO}_{2}$ and $\mathrm{Al}_{2} \mathrm{O}_{3}$ nanofluids at various mass concentrations. Water was used as the working fluid in their PHP. It was found out nanofluid had improved the thermal resistance value by $69.37 \%$ as compared to water.

Seemingly, the effect of nanofluid type in PHP has not been comprehensively studied. Thus, numerical experiments were conducted by using silver $\left(\mathrm{Ag}-\mathrm{H}_{2} \mathrm{O}\right)$, Diamond- $\mathrm{H}_{2} \mathrm{O}$, silica oxide $\left(\mathrm{SiO}_{2}-\right.$ $\mathrm{H}_{2} \mathrm{O}$ ) nanofluids, water and the results were reported in the current work. The ANSYS FLUENT software was used for the simulation purpose. Constant heat flux of $1000 \mathrm{~W} / \mathrm{m}^{2}$ and filling ratio of $50 \%$ were used throughout the numerical study. 


\section{CFD FLUENT ANSYS Simulation}

\subsection{Numerical Modeling}

The numerical model (2D three-turns PHP) was generated using Design Modeler (DM) which is a part of ANSYS FLUENT 18.1 software. Figure 1 shows that the PHP consists of three sections, i.e. condenser, adiabatic section, and evaporator. The total length is $203.2 \mathrm{~mm}$. The heat pipe channel is separated at a distance of $4 \mathrm{~mm}$. There are 12 probe points as shown in Figure 1, which were used to measure the temperature at the specified position in the evaporator and condenser sections. This three-turn PHP model mimics the PHP model reported in the Malay S. Patel's paper [8]. This numerical model was then subjected to different operating conditions. The predicted temperature was then compared with that reported by Malay S. Patel for validation purpose.

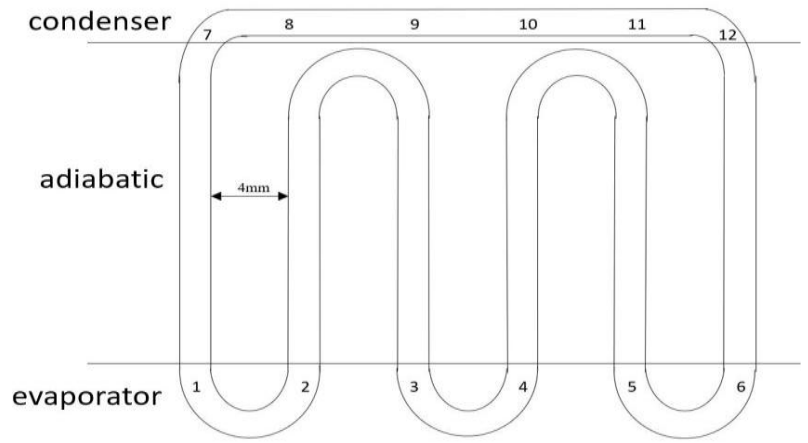

Fig. 1: 2-D Three turns PHP model

Table 1 shows the dimensions of the 2D PHP model for adiabatic evaporator and condenser sections. The tube diameter in this model is smaller than that reported in literature which is typically 3 $\mathrm{mm}$ in order to mimic the dimensions employed by Malay S. Patel [8]. The tube diameter plays a dominant role in affecting the thermal resistance.

Table 1: Three turns 2-D PHP dimensions

\begin{tabular}{|c|c|}
\hline 2D PHP Specification & Dimension $(\mathrm{mm}) /$ Area $\left(\mathrm{m}^{2}\right)$ \\
\hline Condenser length & 59.2 \\
\hline Adiabatic length & 84 \\
\hline Evaporator length & 60 \\
\hline Channel diameter & 0.8 \\
\hline Length between channel & 4 \\
\hline Condenser surface area & 0.0534605 \\
\hline Adiabatic surface area & 0.327725 \\
\hline Evaporator surface area & 0.0451874 \\
\hline
\end{tabular}

\subsection{Meshing}

A conformal quadrilateral mesh of size 0.0004 was generated. The quadrilateral mesh is better than the triangular mesh in terms of simulation accuracy and stability as the quadrilateral mesh has a lower skewness value. The total number of meshes and nodes generated was 4280 and 1070, respectively.

\subsection{Fluent Model Setup}

\subsubsection{Volume of Fluid (VOF) Model}

The solver setup for the current simulation followed that reported by Umberto Costa [9]. Both double precision and serial processing options were selected. The pressured-based solver was used and the gravitational acceleration was fixed at $9.81 \mathrm{~m} / \mathrm{s}^{2}$ in the negative Y-axis direction. The volume of fluid method was used to track the gas-liquid interface [10]. In VOF model, the volume fraction value of a cell $\alpha_{q}$ determines the cell properties as follows:

$$
\begin{array}{ll}
-\alpha_{q}=0 & : \text { the cell is empty (of the } q^{\text {th }} \text { fluid). } \\
-\alpha_{q}=1 & : \text { the cell is full (of the } q^{\text {th }} \text { fluid). } \\
-0 \leq \alpha_{q} \leq 1 & : \text { the cell contains the interface. }
\end{array}
$$

The energy equation was turned on and flow was treated as a laminar with viscous heating. The flow inside the PHP is governed by the conservations of mass, momentum, and energy as follows [11]:

$\nabla \vec{u}=0$

$$
\begin{aligned}
& \left.\left.\frac{\partial(\rho \vec{u})}{\partial t}+\nabla \cdot(\vec{u} \cdot \rho \vec{u})=-\nabla p+\nabla \cdot[\mu / \nabla \vec{u})+(\nabla \vec{u})^{T}\right)\right]+\vec{f}_{\sigma} \\
& \frac{\partial(p c T)}{\partial t}+\nabla \cdot(\rho c \underset{u}{\longrightarrow} T)=\nabla \cdot(k \nabla T)
\end{aligned}
$$

where $\rho$ is the fluid density, $\vec{u}$ is the velocity vector, $p$ is the fluid pressure, $\mu$ is the fluid dynamic viscosity, $c$ is the fluid specific heat capacity, $T$ is the fluid temperature and $k$ is the fluid thermal conductivity. The term $\vec{f}_{\sigma}$ is the surface tension force.

Firstly, the suitability of a working fluid to be used in the PHP should be identified. The main requirements are thermal stability, compatibility with heat pipe material, high thermal conductivity, and low liquid and vapor viscosities. Furthermore, the working fluid must be low in latent heat, high in specific heat, low in surface tension, and low in dynamic viscosity for effective operation in PHP. By incorporating nanofluid in the simulation, its thermophysical properties such as thermal conductivity, density, viscosity and specific heat values should be determined. Various models have been reported in the literature; however, none of them can be recognized as the most accurate model for calculating the thermalphysical properties are expressed in Equations (4) to (7) ([12], [13], [14], [15], [16]).

$$
\begin{aligned}
& \rho_{n f}=(1-\varphi) \rho_{b f}+\varphi \rho_{p} \\
& \left(\rho c_{p}\right)_{n f}=(1-\varphi)\left(\rho c_{p}\right)_{b f}+\varphi\left(\rho c_{p}\right)_{p} \\
& k_{n f}=\frac{k_{p}+2 k_{b f}+2\left(k_{p}-k_{b f}\right) \varphi}{k_{p}+2 k_{b f}-\left(k_{p}-k_{b f}\right) \varphi} \\
& \mu_{n f}=\mu_{b f}(1+2.5 \varphi)
\end{aligned}
$$

Here, the particle mass concentration is denoted as " $\varphi$ ". The terms nanofluid, based fluid and particle are symbolized as " $n f$ ", " $b f$ " and " $p$ ". For all the nanofluids considered in the current study $\left(\mathrm{SiO} 2-\mathrm{H} 2 \mathrm{O}, \mathrm{Ag}-\mathrm{H}_{2} \mathrm{O}\right.$ or Diamond- $\mathrm{H}_{2} \mathrm{O}$ ), the particle concentration of $0.02 \%$ was used. Their thermophysical properties are presented in Table 2.

Table 2: Nanofluids thermo-physical properties and water $\mathrm{SiO} 2-\mathrm{H}_{2} \mathrm{O}$ concentration $(0.02 \%)$

\begin{tabular}{|c|c|c|}
\hline \multicolumn{3}{|c|}{$\mathrm{SiO} 2-\mathrm{H}_{2} \mathrm{O}$ concentration $(0.02 \%)$} \\
\hline Properties & Nanoparticles & Nanofluid \\
\hline $\begin{array}{c}\text { Thermal conductivity } \\
\text { (W/mK) }\end{array}$ & 1.2 & 0.6219 \\
\hline Specific heat $(\mathrm{J} / \mathrm{Kg} . \mathrm{K})$ & 703 & 4032.2537 \\
\hline Viscosity $\left(\mathrm{Ns} / \mathrm{m}^{2}\right)$ & - & 0.0011 \\
\hline
\end{tabular}




\begin{tabular}{|c|c|c|}
\hline Density $\left(\mathrm{Kg} / \mathrm{m}^{3}\right)$ & 2200 & 1022.2361 \\
\hline \multicolumn{3}{|c|}{$\mathrm{Ag}-\mathrm{H}_{2} \mathrm{O}$ concentration $(0.02 \%)$} \\
\hline $\begin{array}{l}\text { Thermal conductivity } \\
(\mathrm{W} / \mathrm{mK})\end{array}$ & 429 & 0.6504 \\
\hline Specific heat (J/Kg.K) & 235 & 3484.4365 \\
\hline Viscosity $\left(\mathrm{Ns} / \mathrm{m}^{2}\right)$ & - & 0.0011 \\
\hline Density $\left(\mathrm{Kg} / \mathrm{m}^{3}\right)$ & 10500 & 1188.2363 \\
\hline \multicolumn{3}{|c|}{ Diamond- $\mathrm{H}_{2} \mathrm{O}$ concentration $(0.02 \%)$} \\
\hline $\begin{array}{l}\text { Thermal conductivity } \\
(\mathrm{W} / \mathrm{mK})\end{array}$ & 1000 & 0.6505 \\
\hline Specific heat (J/Kg.K) & 497.26 & 3935.2813 \\
\hline Viscosity $\left(\mathrm{Ns} / \mathrm{m}^{2}\right)$ & - & 0.0011 \\
\hline Density $\left(\mathrm{Kg} / \mathrm{m}^{3}\right)$ & 3510 & 1048.4362 \\
\hline \multicolumn{3}{|c|}{ Water } \\
\hline $\begin{array}{l}\text { Thermal conductivity } \\
(\mathrm{W} / \mathrm{mK})\end{array}$ & - & 0.613 \\
\hline Specific heat (J/Kg.K) & - & 4182 \\
\hline Viscosity $\left(\mathrm{Ns} / \mathrm{m}^{2}\right)$ & - & 0.00103 \\
\hline Density $\left(\mathrm{Kg} / \mathrm{m}^{3}\right)$ & - & 998.2 \\
\hline
\end{tabular}

The thermal conductivities of diamond and silver nanofluids are almost similar and about $4.4 \%$ higher than that of $\mathrm{SiO}_{2}$ nanofluid. Higher thermal conductivity leads to better thermal performance; however, this parameter alone is not sufficient to justify the thermal performance. Other variables such as viscosity, specific heat and density should be considered as well in order to understand the thermal behaviors of these nanofluids.

\subsubsection{Boundary Conditions}

At the evaporator sections of surface area $0.04518 \mathrm{~m}^{2}$, constan heat flux of $1000 \mathrm{~W} / \mathrm{m}^{2}$ was imposed as shown in Figure 2. The red line shown in the evaporator section indicates the heat flux location.

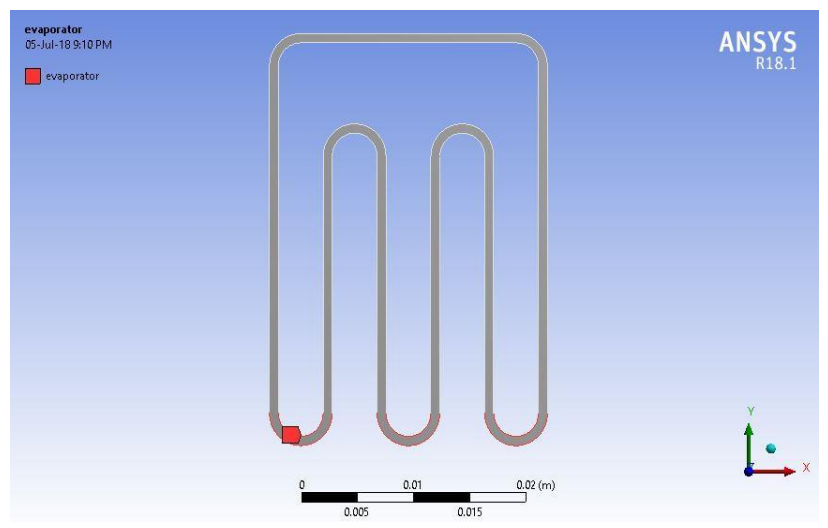

Fig. 2: Boundary conditions (Heat applied to the evaporator)

The degree of pulsation in PHP is very dependent on the intensity of heat flux as low heat flux may cause unnoticeable or weak flow oscillation in the PHP. At the condenser section, a fixed temperature of $300 \mathrm{~K}$ was applied. Meanwhile, the heat flux of $0 \mathrm{~W} / \mathrm{m}^{2}$ was set at the adiabatic section. The number of mass transfer mechanisms was treated as 1 in order to activate the phase change process between liquid and vapor phases (evaporation and condensation mechanism). The saturation temperature was specified as $308 \mathrm{~K}$. The surface tension coefficient was prescribed as $0.07 \mathrm{~N} / \mathrm{m}$. Before patching was done, the flow region was separated. The top part was initially filled with air (volume fraction of air is 1) and the bottom part was filled with liquid (volume fraction of water/nanofluid is 1).

The number of time steps was set as 30,000 with the time step size of $0.0001 \mathrm{~s}$ was used. The maximum number of iterations of each time loop was set as 7 . Therefore, the total simulation time was 3.0s, which was similar to the one reported in the literature. Due to the coupling between different phases, the computational time is very long. Also, the flow accuracy is sensitive to the time step size, $\square t$ [15]. It was calculated from Equation (8) where $C_{F L}$ is the Courant number set as $0.25, \square x$ is the mesh size $(=0.0004)$ and $v$ is the fluid velocity (taken as 1$)$.

$\Delta t=\frac{C_{F L} \Delta x}{v}$

\section{Results and Discussions}

\subsection{Volume Fraction Contour}

\subsubsection{Water}

Figure 3 (a) represents the volume fractions of water liquid in the PHP model at $0 \mathrm{~s}$. The red color indicates the liquid fraction while the blue color indicates the vapor fraction. Initially, vapor formation was not visible and PHP was half filled with water. However, at $0.5 \mathrm{~s}$, the liquid started to vaporize in the PHP and bubbles started to appear at various spots mainly within the evaporator section as shown in Figure 3 (b). Figure 3 (c) shows the flow development at $3 \mathrm{~s}$ time. The vapor rose to the condenser section and condensed to become liquid again. This process repeats itself as long as there is heat supply from the evaporator section and there is no dry out of working fluid in the PHP. Liquid plugs having abnormal menisci were apparent in the plug edges due to the intensive nucleate boiling and superheated vapor formation [17]. Abnormal menisci could be attributed to small channel diameter used in this study and high heat flux supplied to the evaporator as well. Higher surface tension will cause higher capillary resistance and influence the internal pressure fluctuation of PHP. The liquid that has lower surface tension which can give better thermal performance.

(a)
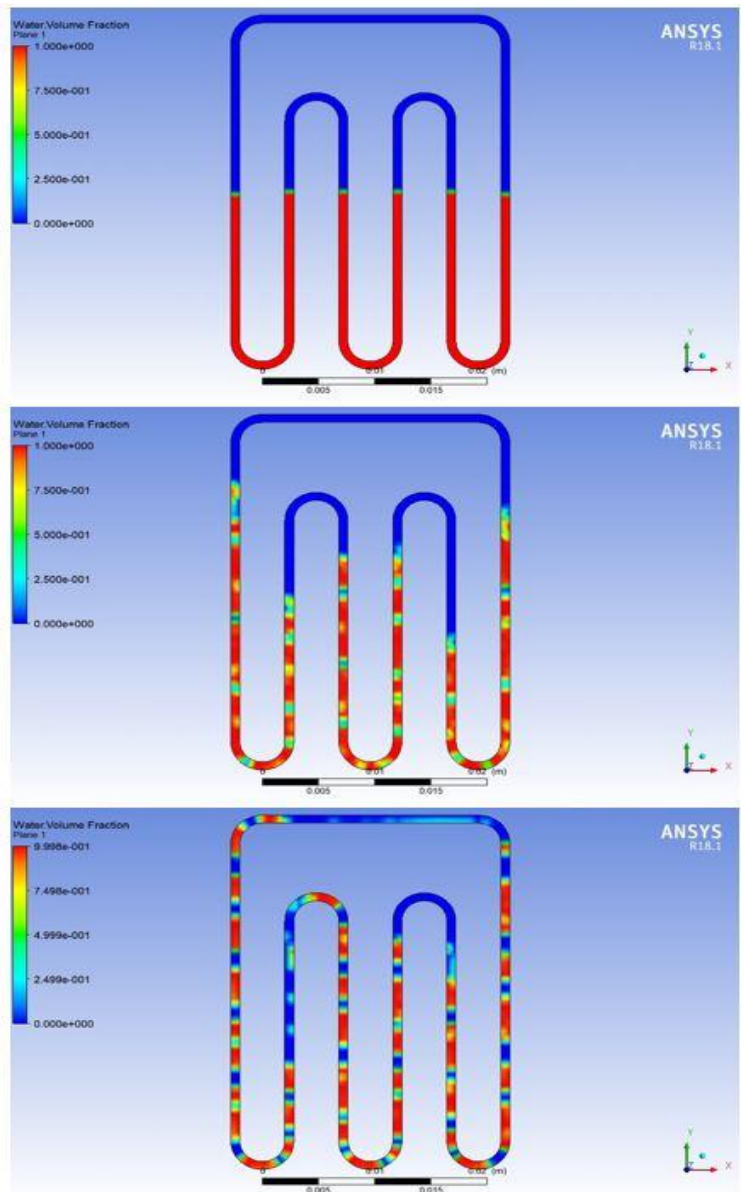

Fig. 3: Volume fractions of liquid and vapor slugs of water at (a) $t=0 \mathrm{~s}$, (b) $\mathrm{t}=0.5 \mathrm{~s},(\mathrm{c}) \mathrm{t}=3 \mathrm{~s}$ 


\subsubsection{Nanofluids}

The volume fractions at $\mathrm{t}=3 \mathrm{~s}$ of $\mathrm{Ag}-\mathrm{H}_{2} \mathrm{O}, \mathrm{SiO}_{2}-\mathrm{H}_{2} \mathrm{O}$, and Diamond- $\mathrm{H}_{2} \mathrm{O}$ nanofluids are shown in Figure 4 (a), (b) and (c). Similarly, liquid-vapor slug flow condition was observed in the PHP. The flow behavior of $\mathrm{SiO}_{2}$ nanofluid was quite similar to that of water as the fluid was able to reach the condenser section. However, for diamond and silver nanofluids, the liquid-vapor slugs were only about to enter the condenser section. This is because the specific heats of $\mathrm{SiO}_{2}$ nanofluid and water are higher, hence, they can transfer more heat and promote the oscillation in the PHP.

(a)

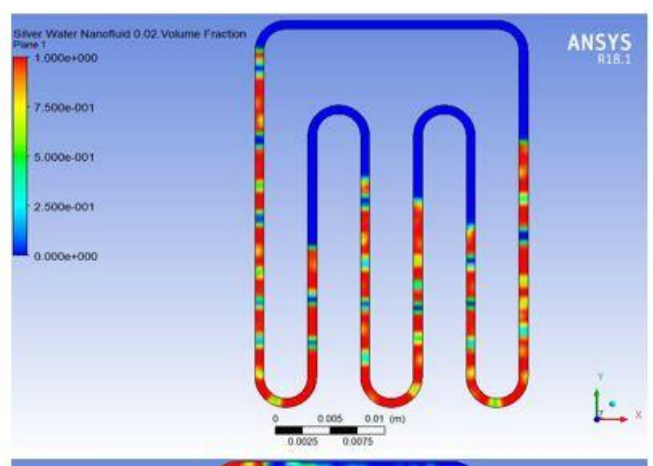

(b)

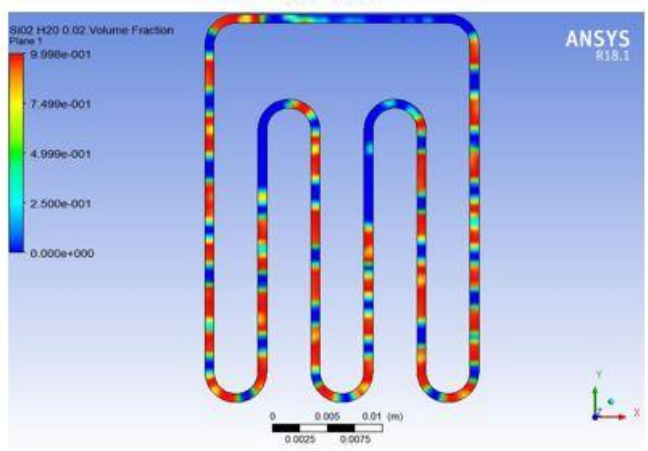

(c)

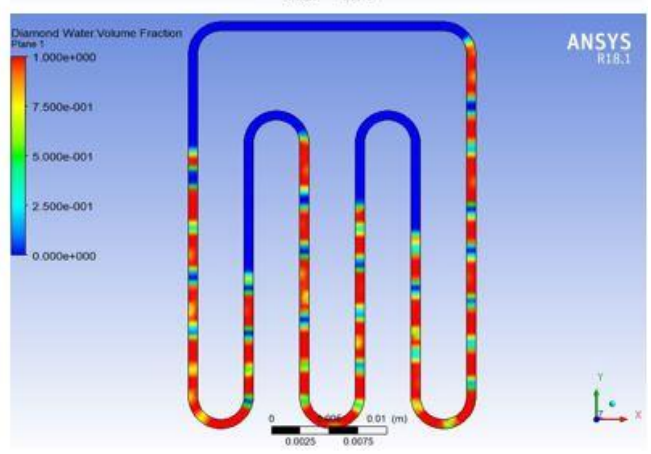

Fig. 4: Volume fraction contour at $\mathrm{t}=3 \mathrm{~s}$ for nanofluids of (a) $\mathrm{Ag}-\mathrm{H}_{2} \mathrm{O}$, (b) $\mathrm{SiO}_{2}-\mathrm{H}_{2} \mathrm{O}$, and (c) Diamond- $\mathrm{H}_{2} \mathrm{O}$

\subsection{Validation of Numerical Analysis}

The current numerical results were compared with the simulation and experimental results reported by Malay S. Patel [8] and Hongwei Jia et al. [18]. Table 3 presents the percentage of deviation between the current simulation and the result reported by Malay S. Patel for the case of water.

Table 3: Percentage of deviation for working fluid of water for temperature results between the current study and the Malay S. Patel's study

\begin{tabular}{|c|c|c|c|c|}
\hline Temperature & $\begin{array}{c}\text { No of } \\
\text { turns }\end{array}$ & $\begin{array}{c}\text { Current } \\
\text { study }\end{array}$ & $\begin{array}{c}\text { Malay S. } \\
\text { Patel }\end{array}$ & $\begin{array}{c}\text { Deviation } \\
(\%)\end{array}$ \\
\hline $\begin{array}{c}\text { Average tem- } \\
\text { perature of } \\
\text { evaporator (K) }\end{array}$ & 1 & 309.4 & 309.66 & 0.08 \\
\cline { 1 - 3 } $\begin{array}{c}\text { Average tem- } \\
\text { perature of }\end{array}$ & 1 & 297.73 & 298.64 & 0.3 \\
\cline { 1 - 4 } & & & & \\
\hline
\end{tabular}

\begin{tabular}{|c|c|c|c|c|}
\hline condenser (K) & & & 314.36 & 2.39 \\
\hline $\begin{array}{c}\text { Average tem- } \\
\text { perature of } \\
\text { evaporator (K) }\end{array}$ & \multirow{2}{*}{2} & 306.84 & 287.74 & 2.44 \\
\cline { 1 - 3 } $\begin{array}{c}\text { Average tem- } \\
\text { perature of } \\
\text { condenser (K) }\end{array}$ & & 294.94 & 331.31 & 7.68 \\
\cline { 1 - 3 } $\begin{array}{c}\text { Average tem- } \\
\text { perature of } \\
\text { evaporator (K) }\end{array}$ & \multirow{2}{*}{3} & 294.41 & 298.1 & 1.23 \\
\cline { 1 - 3 } $\begin{array}{c}\text { Average tem- } \\
\text { perature of } \\
\text { condenser (K) }\end{array}$ & 3 & & & \\
\cline { 3 - 5 } & & & & \\
\hline
\end{tabular}

The highest percentage of deviation was $7.68 \%$ at the evaporator of 3-turn PHP, while the lowest percentage of deviation was $0.08 \%$ at the evaporator of 1-turn PHP. The average temperature at the evaporator of the 3-turn PHP deviated by $9.8 \%$ from the experimental data reported by Hongwei Jia et al. [18].

\subsection{Thermal Performance}

\subsubsection{Effect of Incorporating Nanofluid in PHP}

The main objective of this study was to investigate the effectiveness of using nanofluid as the working fluid in the PHP. The average temperatures of the condenser and evaporator and the thermal resistance for respective working fluids are presented in Table 4. In order to identify the thermal performance, the thermal resistance values are calculated from Equation (9), where $Q$ is the constant heat input use in this study $(=45.18 \mathrm{~W}) . T_{\text {evp }}$ and $T_{\text {cond }}$ are the average temperatures at the evaporator and condenser sections, respectively.

$R=\frac{T_{e v p}-T_{\text {cond }}}{Q}$

Table 4: Temperature and thermal resistance of nanofluids and water in PHP

\begin{tabular}{|c|c|c|c|c|}
\hline $\begin{array}{c}\text { Working } \\
\text { fluid }\end{array}$ & $\begin{array}{c}\text { Average } \\
\text { temperature } \\
\text { evaporator } \\
(\mathrm{K})\end{array}$ & $\begin{array}{c}\text { Average } \\
\text { temperature } \\
\text { condenser } \\
(\mathrm{K})\end{array}$ & $\begin{array}{c}\text { Average } \\
\text { temperature } \\
\text { difference } \\
\Delta T\end{array}$ & $\begin{array}{c}\text { Thermal } \\
\text { resistance } \\
(\mathrm{K} / \mathrm{W})\end{array}$ \\
\hline $\begin{array}{c}\text { Diamond- } \\
\mathrm{H}_{2} \mathrm{O}\end{array}$ & 308.29 & 304.82 & 3.47 & 0.0768 \\
\hline $\mathrm{SiO}_{2}-\mathrm{H}_{2} \mathrm{O}$ & 298.55 & 294.05 & 4.5 & 0.0997 \\
\hline $\mathrm{Ag}-\mathrm{H}_{2} \mathrm{O}$ & 308.41 & 304.84 & 3.57 & 0.0791 \\
\hline Water & 305.86 & 294.41 & 11.45 & 0.2535 \\
\hline
\end{tabular}

From the results, diamond nanofluid gives the best thermal performance as its thermal conductivity is $1000 \mathrm{~W} / \mathrm{mK}$ which is the highest as compared to those of other nanoparticles. Typically, higher thermal conductivity will lead to better heat transfer. The average temperatures difference of evaporator and condenser for diamond and silver nanofluids are smaller than those in $\mathrm{SiO}_{2}$ nanofluid and water. A lower average temperature difference between evaporator and condenser will result in lower thermal resistance. This is one of the main reason diamond and silver nanofluids are better in thermal performance as compared to $\mathrm{SiO}_{2}$ nanofluid and water. The thermal resistance of $\mathrm{SiO}_{2}$ nanofluid is the highest among other nanofluid used in this study due to its lowest nanoparticle thermal conductivity $(1.2 \mathrm{~W} / \mathrm{mK})$.

From these results, it can be deduced that higher thermal conductivity will give lower thermal resistance and improve the thermal performance in the PHP. This will promote the heat transfer rate in the fluid and cause the formation of molecular nanolayer on the surface of nanoparticles [19]. A higher heat supply is more suitable for fluids of large specific heat. In this simulation, diamond and silver nanofluids are preferable at the heat input of $45.18 \mathrm{~W}$ as they have lower specific heats as compared to water and $\mathrm{SiO}_{2}$ 
nanofluid. Possibly, water and $\mathrm{SiO}_{2}$ nanofluid may yield a better thermal performance at heat input of more than $45.18 \mathrm{~W}$. On the other hand, the thermal resistance of water is higher than that of diamond nanofluid by $69.7 \%$. Diamond nanofluid has the lowest thermal resistance amongst all working fluids considered.

Figure 5 shows the temperature contour in the PHP for $\mathrm{Ag}-\mathrm{H}_{2} \mathrm{O}$ nanofluid at $3 \mathrm{~s}$. At the evaporator section, the temperature is higher due to the heat flux applied. Conversely, the temperature is lower at the condenser section due to heat rejection.

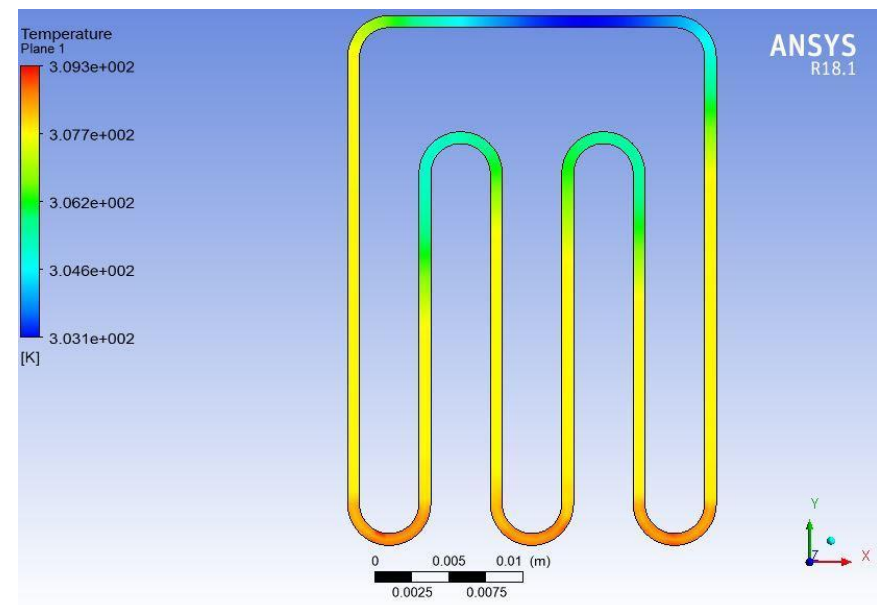

Fig. 5: Temperature contour of $\mathrm{Ag}-\mathrm{H}_{2} \mathrm{O}$ nanofluid

\subsubsection{Effect of Number of PHP Turns on Thermal Resistance}

The effect of number of turns in the PHP was studied as well. Water was used as the working fluid in this study. The thermal resistance results of 1,2 and 3-turn PHP are calculated and presented in Figure 6. The lowest thermal resistance value of 0.25 $\mathrm{K} / \mathrm{W}$ was observed for the 3-turn PHP; its thermal performance was $67.1 \%$ better than that of the 1-turn PHP. From Figure 6, it was observed that higher number of turns would give lower thermal resistance. Large number of channels in the PHP will create more complex hydrodynamics and more intense temperature imbalance between the channels. Larger number of turns tends to promote pulsation in the PHP which will increase the heat transfer rate.

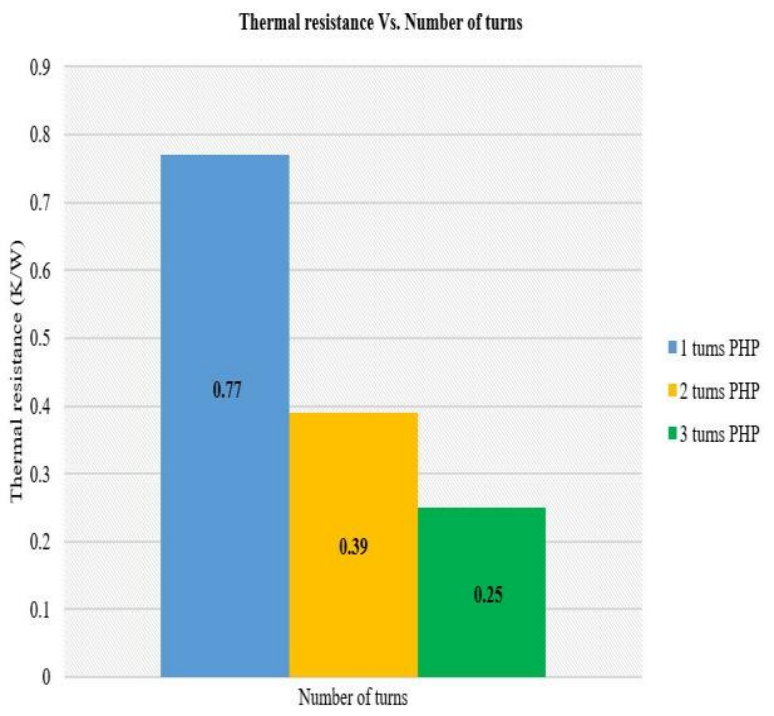

Fig. 6: Effect of the number of PHP turn on thermal resistance

Figure 7 shows the volume fraction contours for 1, 2 and 3-turn PHP at $t=3 \mathrm{~s}$. Formation of menisci at the liquid edges can be seen at all PHP turns. Liquid-bubble plugs in the 2-turn PHP are able to move into the condenser section fully. (a)

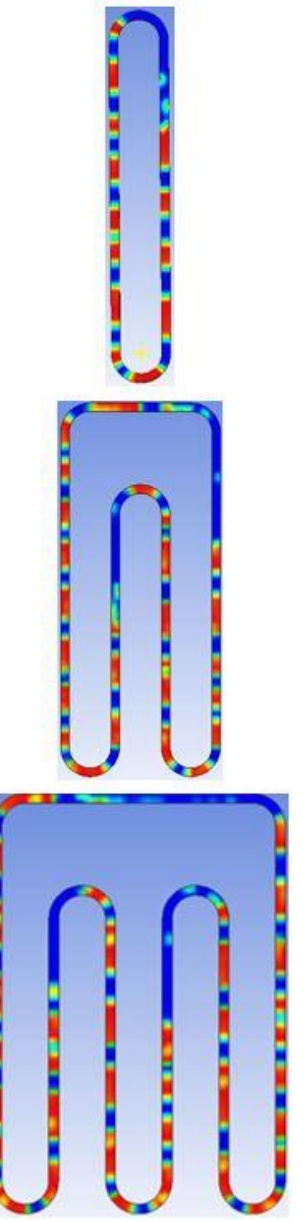

Fig. 7: Volume fraction contour for PHP in different number of turns at time, $\mathrm{t}=3 \mathrm{~s}$; (a) 1 turn, (b) 2 turn, (c) 3 turn.

\section{Conclusion}

The numerical models of 2D PHP incorporating silver $\left(\mathrm{Ag}-\mathrm{H}_{2} \mathrm{O}\right)$ nanofluid, Diamond- $\mathrm{H}_{2} \mathrm{O}$ nanofluid, silica oxide $\left(\mathrm{SiO}_{2}-\mathrm{H}_{2} \mathrm{O}\right)$ nanofluid and water have been simulated successfully using ANSYS FLUENT software. Some conclusions can be made:

1. The volume fraction contour shows that two-phase liquidvapor slug oscillation flow occurs in PHP. The liquid has meniscus at the edge of the plugs due to the surface tension.

2. Higher number of turns in PHP leads to better thermal performance and lower thermal resistance. The formation of liquid-bubbles is visible as well in 1- and 2-turn PHP.

3. Nanofluid can indeed improve the thermal performance of PHP as compared to using water alone. Diamond nanofluid exhibits the best thermal performance, which is $69.7 \%$ higher than that of water.

\section{Acknowledgment}

The author would like to sincerely thank the Ministry of Higher Education (MOHE) of Malaysia for the provision of a grant with code no 20160103FRGS to support this work.

\section{References}

[1] N. S. Sree, N. V. S. S. Sudheer, and P. Bhramara, "THERMAL ANALYSIS OF CLOSED LOOP PULSATING HEAT PIPE," vol. 8, no. 2, pp. 21-36, 2018.

[2] B. Fadhl, L. C. Wrobel, and H. Jouhara, "Modelling of the thermal behaviour of heat pipes," vol. 83, pp. 377-389.

[3] H. Yang, S. Khandekar, and M. Groll, "Performance characteristics of pulsating heat pipes as integral thermal spreaders," Int. J. Therm. 
Sci., vol. 48, no. 4, pp. 815-824, 2009.

[4] Y. Xuan and Q. Li, "Heat transfer enhancement of nanofluids," Int. J. heat fluid flow, vol. 21, no. 1, pp. 58-64, 2000.

[5] M. Alhuyi, R. Ghasempour, and M. Hossein, "Experimental investigation of graphene oxide nano fl uid on heat transfer enhancement of pulsating heat pipe," vol. 91, pp. 90-94, 2018.

[6] O. Nanofluid, "Journal of Energy \& Environment," pp. 38-46.

[7] E. J. Johnson, S. M. Joshi, and R. K. Sarangi, "Performance of Closed Loop Pulsating Heat Pipe : A Numerical Analysis,” vol. VI, no. Vii, pp. 91-94, 2017.

[8] M. S. Patel, S. D. Mane, S. S. Mopare, and D. Y. Patil, "Comparison of Heat Transfer rate of closed loop micro pulsating heat pipes having different number of turns," Int. J. Eng. Sci., vol. 06, no. 07, pp. 01-12, 2017.

[9] T. Report, "CFD simulation of a Pulsating Heat Pipe using ANSYS FLUENT," no. July, 2016.

[10] A. K. Singh, "Numerical Analysis of Performance of Closed- Loop Pulsating Heat Pipe A THESIS SUBMITTED IN PARTIAL FULFILLMENT OF THE Numerical Analysis of Performance of Closed- Loop Pulsating Heat Pipe,” no. June, p. 56, 2013.

[11] J. Venkata Suresh and P. Bhramara, "CFD Analysis of Multi turn Pulsating Heat pipe," Mater. Today Proc., vol. 4, no. 2, pp. 2701$2710,2017$.

[12] N. M. Zahari, K. H. Chua, and L. M. Sidek, "Journal of Energy \& Environment," J. Energy Environ., pp. 18-23, 2014.

[13] J. T. Cieśliński, A. Fiuk, W. Miciak, and B. Siemieńczuk, "Performance of a Plate Heat Exchanger Operated with WaterAl\&lt;sub\&gt;2\&lt;/sub\&gt;O\&lt;sub\&gt;3\&lt;/sub\&gt; Nanofluid," Appl. Mech. Mater., vol. 831, no. April, pp. 188-197, 2016.

[14] S. Mojumder, S. Saha, S. Saha, and M. A. H. Mamun, "Effect of magnetic field on natural convection in a $\mathrm{C}$-shaped cavity filled with ferrofluid," Procedia Eng., vol. 105, no. Icte 2014, pp. 96-104, 2015.

[15] Y. Xuan and W. Roetzel, "Conceptions for heat transfer correlation of nanofluids," Int. J. Heat Mass Transf., vol. 43, no. 19, pp. 37013707, 2000.

[16] A. Einstein, "On the Motion of Small Particles Suspended in a Stationary Liquid, as Required by the Molecular Kinetic Theory of Heat," Ann. Phys., vol. 322, pp. 549-560, 1905.

[17] S. M. Pouryoussefi and Y. Zhang, "Analysis of chaotic flow in a 2D multi-turn closed-loop pulsating heat pipe," Appl. Therm. Eng., vol. 126, pp. 1069-1076, 2017.

[18] H. Jia, L. Jia, and Z. Tan, "An experimental investigation on heat transfer performance of nanofluid pulsating heat pipe," J. Therm. Sci., vol. 22, no. 5, pp. 484-490, 2013.

[19] J. Qu and H. Wu, "Thermal performance comparison of oscillating heat pipes with $\mathrm{SiO} 2 /$ water and $\mathrm{A} 12 \mathrm{O} 3$ /water nanofluids," Int. J. Therm. Sci., vol. 50, no. 10, pp. 1954-1962, 2011. 